\title{
PENGARUH AKTIVITAS MENANYA BERBASIS MASALAH DENGAN METODE SAINTIFIK TERHADAP PROSES KOGNITIF SISWA
}

\author{
I Made Suarjana, I Wayan Widiana, dan Ni Luh Putu Nila Cahyani \\ Fakultas Ilmu Pendidikan Universitas Pendidikan Ganesha \\ email: wayan_widiana@yahoo.co.id
}

\begin{abstract}
Abstrak
Penelitian ini bertujuan untukmelihat pengaruh aktivitas pembelajaranmenanya berbasis masalah dengan pendekatan saintifik terhadap kognitif siswa kelas IV sekolah dasar (SD). Penelitian ini merupakan penelitian quasi eksperimen dengan rancangan posttest only control group design. Populasi dalam penelitian ini adalah kelas IV SD di sekolah Rintisan Kurikulum 2013 di Kabupaten Buleleng Tahun Pelajaran 2016/2017. Total populasi berjumlah 353 orang yang terbagi menjadi 11 kelas di antaranya terdapat kelas pararel. Sampel diambil dengan menggunakan teknik simple random sampling menghasilkan 73 siswa yang kemudian terbagi menjadi dua kelas. Metode pengumpulan data yang digunakan adalah tes esai yang sudah divalidasi secara konten dan empirik. Sebelum data dianalisa menggunakan T-test, data juga diuji menggunakan uji normalitas distribusi data terhadap keseluruhan unit analisis, dan ujihomogenitas varian antarkelompok. Hasil penelitian menunjukkan adanya perbedaan yang signifikan dimensi proses kognitif antara kelompok siswa yang diberikan aktivitas pembelajaran menanya berbasis masalah. dalam pendekatan saintifik dengan kelompok siswa yang diberikan aktivitas pembelajaran konvensional. Dapat disimpulkan bahwa aktivitas pembelajaran menanya berbasis masalah dalam pendekatan saintifik dapat meningkatkan kognitif siswa IV SD.
\end{abstract}

Kata kunci: dimensi proses kognitif, menanya, pembelajaran tematik berbasis masalah

\section{OPTIMIZATION OF DIMENSIONS OF COGNITIVE PROCESS IN THEMATIC LEARNING BASED ON PROBLEM}

\begin{abstract}
This study aimed to find out the effect of problem-based learning activities using scientific approach on the students' cognitive skill. This research was a quasi-experimental study with a posttest only control group design. The population in this study was the fourth grade elementary school in the 2013 in Pilot Elementary School in Buleleng year 2016/2017. From 353 total population, the sample was taken using simple random sampling technique which resulted in 73 students who were then divided into two classes. The data collection method used was content and empirical validated essay test. Before the data were analyzed using the T-test, the data were also tested using the data distribution normality test for the entire unit of analysis, and the homogeneity test of the variance between groups. There were significant differences in the dimensions of cognitive processes between groups of students who were given problem-based questioning learning activities in a scientific approach and the groups of students who are given conventional learning activities. The results show that the problem-based learning activity of asking questions in a scientific approach is able to improve the cognitive of the fourth grade students.
\end{abstract}

Keywords: cognitive process dimensions, questioning, and problem-based thematic learning 


\section{PENDAHULUAN}

Kurikulum 2013 merupakan inovasi pendidikan yang diharapkan mampu menjadi wadah pengembangan dan peningkatan kualitas pendidikan. Dalam Kurikulum 2013, proses pembelajaran berlangsung dengan memadukan penalaran induktif dengan penalaran deduktif yang dikenal dengan sebutan pendekatan saintifik. Pendekatan saintifik merupakan kegiatan pembelajaran yang meliputi kegiatan mengamati, bertanya, menalar dan mengumpulkan data serta mengkomunikasikan (Anjarsari, 2019; In'am \& Hajar, 2017; Sutarto, Jaedun \& Raharjo, 2017). Setiap kegiatan yang sesuai untuk pekerjaan ilmiah dapat dikatakan penalaran induktif, melihat kesimpulan umum dapat diperoleh dengan mendasarkan kepada hal tertentu yang diperoleh. Pendekatan saintifik memberikan pemahaman kepada peserta didik dalam mengenai memahami berbagai materi menggunakan pendekatan ilmiah bahwa informasi bisa berasal dari mana saja, kapan saja, tidak bergantung pada informasi searah dari guru (Ambarsari, 2016; Suryani, Renda, \& Wibawa, 2019). Siswa diharapkan melalui pendekatan saintifik bisa menjadi lebih aktif karena keberadaannya menjadi pusat pembelajaran.

Permasalahan yang terjadi saat ini yaitu banyak siswa yang mendapatkan nilai karena guru lebih dominan menggunakan metode konvensional (Andriani, Suarjana, \& Lestari, 2017; Pramana, Jampel, \& Pudjawan, 2018; Wulandari, Sudatha, \& Simamora, 2020). Model pembelajaran konvensional membuat siswa cenderung pasif dalam belajar sehingga berpengaruh pada hasil belajar siswa. Permasalahan ini juga ditemukan pada beberapa sekolah dasar. Berdasarkan hasil observasi ditemukan proses kognitif siswa khususnya kelas IV masih rendah. Rendahnya dimensi proses kognitif siswa tercermin dari hasil tes studi pendahuluan yang diberikan pada siswa yang dapat dilihat pada Tabel 1 .

Tabel 1 menunjukkan bahwa enam SD Rintisan Kurikulum 2013 di Kabupaten Buleleng, nilai rata-rata dari hasil tes studi pendahuluan masih rendah. Selain itu, hasil wawancara dan observasi awal pada 7 Januari 2017 yang dilakukan di sekolah-sekolah Rintisan Kurikulum 2013 di SD Kabupaten Buleleng ditemukan masalah yang hampir sama yaitu masih rendahnya hasil belajar siswa disebabkan

Tabel 1

Hasil Tes Studi Pendahuluan

\begin{tabular}{lllc}
\hline No & Nama Sekolah & Kelas & Rata-rata Kelas \\
\hline 1 & SDN 1 Busungbiu & IV & 44,67 \\
2 & SDN 6 Pejarakan & IV & 61,8 \\
3 & SDN 4 Banyuasri & IV & 60,0 \\
4 & SDN 4 Kaliuntu & IV & 63,8 \\
5 & SDN 3 Banjar Jawa & IVA & 62,06 \\
& & IVB & 64,2 \\
& & IVC & 71,6 \\
6 & SDN 4 Kampung Baru & IVA & 52,56 \\
& & IVB & 57,38 \\
7 & \multirow{2}{*}{ SD Lab Undiksha } & IVA & 67,27 \\
& & IVB & 65,14 \\
\hline
\end{tabular}


oleh beberapa factor. Pertama, ditemukan pada saat melaksanakan pembelajaran tematik dalam pendekatan saintifik tidak berjalan dengan efektif, guru seolaholah masih terbayang mengajar dengan menggunakan kurikulum KTSP. Kedua, guru dalam mengajar masih didominasi dengan metode ceramah sehingga aktivitas pembelajaran dengan pendekatan saintifik belum terlihat jelas. Ketiga, kurangnya bantuan media pembelajaran dalam menyampaikan materi sehingga guru hanya berpatokan pada buku panduan yang telah disediakan. Keempat, guru kurang benar dalam menerapkan pendekatan saintifik. Ada beberapa komponen yang belum dilaksanakan secara optimal. Pendekatan saintifik yang biasa digunakan saat guru mengajar kurang efektif. Salah satu komponen dalam pendekatan saintifik yaitu menanya, guru tidak melaksanakan komponen tersebut dalam pembelajaran saintifik dengan benar. Seharusnya guru melaksanakan komponen menanya dalam pembelajaran dengan seoptimal mungkin.

Berdasarkan permasalahan tersebut, solusi yang ditawarkan untuk mengatasi permasalahan tersebut yaitu dengan menerapkan aktivitas pembelajaran menanya berbasis masalah. Pembelajaran berbasis masalah atau Problem-based Learning adalah pembelajaran yang dapat dikolaborasikan dengan pembelajaran saintifik. Pembelajaran dengan menggunakan pendekatan saintifik akan mampu meningkatkan aktivitas, kreativitas, dan motivasi belajar siswa (Astini, Nurhasanah, \& Nupus, 2019; Widnyani, Dantes, \& Tegeh, 2015). Dengan meningkatnya aktivitas, kreativitas, dan motivasi siswa akan berakibat pada meningkatnya hasil belajar siswa. Penelitian yang dilakukan oleh Putri, Swatra, dan Tegeh (2018) menemukan bahwa model pembelajaran Problembased Learning dapat meningkatkan hasil belajar siswa. Problem-based Learning merupakan model pembelajaran yang memberikan permasalahan nyata kepada siswa sehingga siswa dapat berpikir kritis dalam memecahkan sebuah masalah (Astraman, Dibia, \& Mahadewi, 2017; Nur, Pujiastuti, \& Rahman, 2016; Primayanti, Suarjana, \& Astawan, 2019).

Karakteristik model pembelajaran Problem Based Learning yaitu studentcented yang lebih menitikberatkan kepada siswa sebagai orang yang belajar (Lukitasari, Purnamasari, Utami, \& Sukri, 2019; Nur et al., 2016; Birgili, 2015). Siswa diharapkan secara aktif menggali pengetahuan sendiri lewat masalah yang diberikan dalam pembelajaran. Guru hendaknya merencanakan pembelajaran yang menuntut siswa banyak melakukan aktivitas belajar sendiri atau mandiri agar siswa berperan sebagai pelaku kegiatan belajar. Kognitif siswa diharapkan dapat meningkat melalui pendekatan saintifik.

Penelitian ini bertujuan untuk melihat pengaruh aktivitas pembelajaran menanya berbasis masalah dengan pendekatan saintifik terhadap kognitif siswa kelas IV SD. Peningkatan aspek kognitif dapat mendorong keaktifan siswa dalam belajar.

\section{METODE}

Penelitian ini merupakan penelitian quasi eksperimen dengan rancangan posttest only control group design. Populasi dalam penelitian ini adalah kelas IV SD di sekolah Rintisan Kurikulum 2013 di Kabupaten Buleleng Tahun Pelajaran 2016/2017. Total populasi berjumlah 353 orang yang terbagi menjadi 11 kelas di antaranya terdapat kelas pararel. Sampel diambil dengan menggunakan teknik simple random sampling dengan cara undian yang berjumlah 73 orang terbagi menjadi dua kelas. 
Metode pengumpulan data yang digunakan adalah tes esai yang berjumlah 19 butir soal yang sudah divalidasi secara konten dan empirik. Secara konten, tes yang digunakan sudah memenuhi unsur kompetensi dasar dengan kalimat yang baik sesuai dengan perkembangan psikologis anak usia kelas IV Sekolah Dasar. Sedangkan analisis validasi empirik yang ditinjau dari analisis konsistensi internal tes terhadap 24 butir tes, dan 5 butir tes yang diujikan dinyatakan tidak valid dan 19 butir tes yang diujikan dinyatakan valid. Analisis daya beda butir tes didapatkan 14 butir yang berkualifikasi cukup baik dan 5 butir berkualifikasi kurang baik. Analisis tingkat kesukaran tes didapatkan 14 butir tes berada pada kriteria sedang, dan 5 butir tes berada pada kriteria mudah. Analisis reliabilitas tes dinyatakan bahwa reliabilitas tes berada pada kualifikasi tinggi $(0,76)$. Data pembelajaran tematik dimensi proses kognitif tema 8 subtema 1 dan subtema 2 siswa diambil dengan memberikan posttest pada siswa setelah selesai menerapkan aktivitas pembelajaran menanya berbasis masalah dalam pendekatan saintifik dan menerapkan aktivitas pembelajaran konvensional. Data dianalisis dengan menggunakan uji- $t$.

\section{HASIL PENELITIAN DAN PEMBAHASAN}

Penelitian ini menemukan bahwa pada kelompok eksperimen dimensi proses kognitif siswa setelah mengikuti pembelajaran pendekatan saintifik dalam proses menanya berbasis masalah sebanyak $41,55 \%$ siswa mendapatkan nilai dengan kategori tinggi dan sangat tinggi; $16,67 \%$ siswa mendapatkan nilai dengan kategori sedang dan $21,41 \%$ siswa mendapatkan nilai dengan kategori rendah dan sangat rendah. Hasil berbeda didapatkan pada kelompok control. Pada kelompok kontrol dimensi proses kognitif siswa setelah mengikuti pembelajaran konvensional sebanyak $21,41 \%$ siswa mendapatkan nilai dengan kategori sangat tinggi dan tinggi, serta $78,39 \%$ siswa mendapatkan nilai dengan kategori sedang. Penelitian ini menunjukkan bahwa pada kelompok eksperimen data dimensi proses kognitif siswa cenderung berada pada kategori sedang ke atas, sedangkan pada kelompok kontrol cenderung berada pada kelompok sedang ke bawah. Hasil posttest terhadap 36 orang siswa pada kelompok eksperimen dan terhadap 37 orang siswa kelompok kontrol ditunjukkan pada Tabel 2.

Berdasarkan kriteria skala lima dan sesuai dengan hasil analisis data bahwa mean dimensi proses kognitif tema 8 (tempat tinggalku) subtema 1 dan subtema 2 pada kelompok yang dibelajarkan dengan menggunakan aktivitas pembelajaran menanya berbasis masalah dalam pendekatan saintifik adalah 55,22 (berada pada kategori sangat tinggi). Sebaliknya,

Tabel 2

Hasil Posttest Siswa Kelompok Eksperimen dan Kontrol

\begin{tabular}{cccc}
\hline Rentang Skor Real & $\begin{array}{c}\text { Kelompok } \\
\text { Eksperimen }\end{array}$ & Kelompok Kontrol & Kategori \\
\hline $57,05 \leq \mathrm{X} \leq 76,1$ & $4(11,11 \%)$ & $4(5,41 \%)$ & Sangat Tinggi \\
$44,35 \leq \mathrm{X}<57,05$ & $7(19,44 \%)$ & $11(16 \%)$ & Tinggi \\
$31,65 \leq \mathrm{X}<44,35$ & $4(11,11 \%)$ & $6(21,6 \%)$ & Sedang \\
$18,95 \leq \mathrm{X}<31,65$ & $6(16,67 \%)$ & $8(16,22 \%)$ & Rendah \\
$0,1 \leq \mathrm{X}<18,95$ & $10(28 \%)$ & $6(29,73 \%)$ & Sangat Rendah \\
\hline
\end{tabular}


mean dimensi proses kognitif tema 8 (tempat tinggalku) subtema 1 dan subtema 2 pada kelompok yang dibelajarkan dengan menggunakan aktivitas pembelajaran konvensional adalah 41,16 (berada pada kategori sedang). Hal ini berarti bahwa ratarata dimensi proses kognitif tema 8 (tempat tinggalku) subtema 1 dan subtema 2 siswa kelompok eksperimen lebih tinggi daripada nilai rata-rata dimensi proses kognitif tema 8 (tempat tinggalku) subtema 1 dan subtema 2 siswa kelompok kontrol. Data rata-rata dan standar deviasi hasil posttest kedua kelompok adalah sebagai berikut. Kelompok eksperimen rerata 59,22 dan standar deviasi 10,49. Kelompok kontrol rerata 41,16 dan standar deviasi 8,08.

Sebelum dilakukan pengujian hipotesis dengan uji-t independent terlebih dahulu dilakukan pengujian terhadap prasyarat yang diperlukan terhadap sebaran data hasil penelitian. Uji prasyarat analisis meliputi dua hal, yaitu uji normalitas distribusi data terhadap keseluruhan unit analisis, dan uji homogenitas varian antarkelompok.

Uji normalitas data dilakukan pada keseluruhan unit analisis yaitu kelompok eksperimen dan kelompok kontrol. Analisis yang digunakan pada pengujian normalitas sebaran data adalah analisis $\mathrm{Chi}$ Kuadrat. Proses analisis dibantu dengan menggunakan program MicrosoftExcel 2007 for Windows. Ketentuan normalitas data ditentukan dengan melihat signifikansi hasil analisis. Data berdistribusi normal jika angka signifikansi yang diperoleh lebih dari 0,05 pada taraf signifikansi 5\%. Ringkasan hasil uji normalitas data pada kelompok eksperimen dan kelompok kontrol disajikan pada Tabel 3.

Tabel 3 menunjukkan bahwa nilai signifikansi berada di atas 0,05 untuk semua unit analisis baik menggunakan uji chikuadrat. Artinya, bahwa sebaran data pada kelompok eksperimen berdistribusi normal. Hasil yang hampir sama juga diperoleh pada data kelompok kontrol. Terungkap bahwa nilai signifikansi berada di atas 0,05 untuk semua unit analisis baik menggunakan uji chi-kuadrat. Hal ini menunjukkan bahwa sebaran data pada kelompok kontrol juga berdistribusi normal.

Uji homogenitas varians dilakukan berdasarkan data dimensi proses kognitif pada kelompok eksperimen dan kelompok kontrol. Jumlah masing-masing unit analisis adalah 36 dan 37 orang siswa. Uji homogenitas varians antarkelompok menggunakan uji F. Data dinyatakan homogen jika $\mathrm{F}_{\text {hitung }}<\mathrm{F}_{\text {tabel }}$. Ringkasan hasil uji homogenitas varians antara kelompok disajikan dalam Tabel 4.

Tabel 4 menunjukkan bahwa ringkasan data hasil uji homogenitas varians untuk kedua kelompok model pembelajaran menunjukkan bahwa $\mathrm{F}_{\text {hitung }}<\mathrm{F}_{\text {tabel }}$ yang dibantu dengan program MicrosoftExcel 2007 for Windows. Ini berarti bahwa varians antara kelompok siswa homogen.

Hipotesis penelitian yang diuji adalah terdapat perbedaan yang signifikan dimensi proses kognitif antara kelompok siswa yang diberikan aktivitas pembelajaran menanya berbasis masalah dalam pendekatan saintifik

Tabel 3

Ringkasan Hasil Uji Normalitas Distribusi Data

\begin{tabular}{lccc}
\hline \multirow{2}{*}{ Model Pembelajaran } & \multicolumn{3}{c}{ Chi-Kuadrat } \\
\cline { 2 - 4 } & $\mathrm{T}_{\text {tabel }}$ & $\mathrm{N}$ & $\mathrm{T}_{\text {hitung }}$ \\
\hline Kelompok eksperimen & 7,815 & 36 & 6,768 \\
Kelompok kontrol & 7,815 & 37 & 3,766 \\
\hline
\end{tabular}


Tabel 4

Ringkasan Hasil Uji Homogenitas Varians

\begin{tabular}{lllllll}
\hline Sampel & Mean & $\mathrm{SD}$ & Varians & $\mathrm{F}_{\text {hitung }}$ & $\mathrm{F}_{\text {tabel }}$ & Kesimpulan \\
\hline Kelompok eksperimen & 59,22 & 10,49 & 110,12 & \multirow{2}{*}{1,68} & \multirow{2}{*}{1,74} & $\mathrm{~F}_{\text {hitung }}<\mathrm{F}_{\text {tabel }}$ \\
Kelompok Kontrol & 41,16 & 8,08 & 65,36 & & & \\
\hline
\end{tabular}

dengan kelompok siswa yang diberikan aktivitas pembelajaran konvensional pada kelas IV SD di Kabupaten Buleleng Tahun Pelajaran 2016/2017. Untuk menguji hipotesis digunakan uji-t tidak berkorelasi atau $t$-test independent. Tabel 4 menunjukkan bahwa varian homogen dan jumlah siswa pada tiap kelas yang sama maka pada uji-t tidak berkorelasi ini digunakan rumus polled varians. Ringkasan hasil uji-t tidak berkorelasi disajikan pada Tabel 5.

Berdasarkan hipotesis penelitian yang telah diajukan pada kajian teori kriteria pengujian $\mathrm{H}_{0}$ ditolak jika $\mathrm{t}_{\text {hitung }}>\mathrm{t}_{\text {tabel }}$ dan $\mathrm{H}_{1}$ diterima dengan taraf signifikansi 5\% dan didukung oleh perbedaan skor ratarata yang diperoleh antara kelompok eksperimen yaitu 59,22 yang berada pada kategori sangat tinggi dan kelompok kontrol yaitu 41,16 yang berada pada kategori sedang (cukup tinggi) maka hipotesis alternatif diterima. Ringkasan data hasil uji hipotesis menunjukan hal yang sama bahwa $t_{\text {hitung }}>t_{\text {tabel }}$ sehingga $\mathrm{H}_{0}$ ditolak dan $\mathrm{H}_{1}$ diterima. Dengan demikian, dapat diinterpretasikan bahwa terdapat perbedaan yang signifikan dimensi proses kognitif antara kelompok siswa yang diberikan aktivitas pembelajaran menanya berbasis masalah dalam pendekatan saintifik dengan kelompok siswa yang diberikan aktivitas pembelajaran konvensional pada kelas IV SD di Kabupaten Buleleng Tahun Pelajaran 2016/2017.

Berdasarkan nilai rata-rata dimensi proses kognitif tema 8 (tempat tinggal$\mathrm{ku}$ ) subtema 1 dan subtema 2 pada kelompok siswa yang diberikan aktivitas pembelajaran menanya berbasis masalah dalam pendekatan saintifik adalah 59,22 lebih tinggi daripada kelompok siswa yang diberikan aktivitas pembelajaran konvensional yang nilai rata-rata siswa adalah 41,16. Artinya, bahwa aktivitas pembelajaran menanya berbasis masalah dalam pendekatan saintifik berpengaruh positif terhadap dimensi proses kognitif tema 8 subtema 1 dan subtema 2 siswa kelas IV di Kabupaten Buleleng tahun pelajaran 2016/2017.

Hasil penelitian ini menunjukkan bahwa pada kelompok siswa yang diberikan aktivitas pembelajaran menanya berbasis masalah dalam pendekatan saintifik bahwa pada kelompok eksperimen sebanyak $41,55 \%$ siswa mendapatkan nilai dengan kategori tinggi dan sangat tinggi; $16,67 \%$ siswa mendapatkan nilai dengan kategori sedang; $21,41 \%$ siswa mendapatkan nilai

Tabel 5

Ringkasan Data Hasil Uji Hipotesis

\begin{tabular}{lllllll}
\hline \multicolumn{1}{c}{ Kelompok } & Varian & $\mathrm{N}$ & $\mathrm{Db}$ & $\mathrm{t}_{\text {hitung }}$ & $\mathrm{t}_{\text {tabel }}$ & \multicolumn{1}{c}{ Kesimpulan } \\
\hline Kelompok eksperimen & 10,49 & 36 & 71 & 8,251 & 2,000 & $\mathrm{t}_{\text {hitung }}>\mathrm{t}_{\text {tabel }}$ \\
Kelompok Kontrol & 8,08 & 37 & & & & $\mathrm{H}_{1}$ diterima \\
\hline
\end{tabular}


dengan kategori rendah dan sangat rendah. Aktivitas pembelajaran menanya berbasis masalah dalam pendekatan saintifik dapat meningkatkan hasil belajar siswa hal ini disebabkan oleh beberapa faktor.

Pertama, aktivitas pembelajaran menanya berbasis masalah dalam pendekatan saintifik dapat meningkatkan hasil belajar karena dapat membuat suasana belajar yang menyenangkan bagi siswa. Aktivitas pembelajaran menanya berbasis masalah dalam pendekatan saintifik yang diberikan oleh guru memberikan kenyaman dan ketenangan dalam proses pembelajaran sehingga proses belajar mengajar menjadi kondusif (Ambarsari, 2016; Paut, 2016). Aktivitas pembelajaran yang nyaman akan berdampak pada motivasi siswa dalam belajar yang meningkatkan. Penelitian yang dilakukan oleh Arianti (2017) menyatakan bahwa suasana belajar yang menyenangkan akan meningkatkan kemamupaun siswa dalam menerima materi yang sadang dibelajarkan. Sedangkan penelitian Widodo (2016) menyatakan pembelajaran bermakna dapat diciptakan dengan suasana belajar yang menyenagkan. Pendekatan scientifik dengan Pembelajaran Berbasis Masalah (PBL) membantu siswa menemukan sendiri suatu solusi. PBL melatih siswa untuk memiliki rasa ingin tahu yang tinggi dalam pembelajaran (Nur et al., 2016). Proses pembelajaran pada kelompok siswa yang dibelajarkan dengan memberikan aktivitas pembelajaran menanya berbasis masalah dalam pendekatan saintifik terlihat lebih aktif, menyenangkan, dan termotivasi untuk belajar.

Kedua, aktivitas pembelajaran menanya berbasis masalah dalam pen-dekatan saintifik dapat meningkatkan hasil belajar karena dapat meningkatkan keaktif-an siswa dalam belajar. pembelajaran harus diarahkan agar dapat membangkitkan kreativitas siswa dengan cara belajar berkelompok. Dengan cara berkelompok, siswa dapat berdiskusi satu sama lain, bertukar informasi, dan siswa yang pintar dapat membantu yang kurang pintar (Jahro \& Ridho, 2015; Rosnaeni, Muslimin, \& Saehana, 2018). Pendekatan saintifik merupakan proses pembelajaran yang dirancang sedemikian rupa agar peserta didik secara aktif mengonstruk konsep, hukum atau prinsip melalui tahapantahapan mengamati (untuk mengidentifikasi atau menemukan masalah), merumuskan masalah, mengajukan atau merumuskan hipotesis, mengumpulkan data dengan berbagai teknik, menganalisis data, menarik kesimpulan dan mengomunikasikan konsep, hukum atau prinsip yang ditemukan (Ambarsari, 2016; Sutarto dkk., 2017; Suryani dkk., 2019).

Hasil penelitian ini juga diperkuat oleh Atmojo (2012, p.7) yang mengatakan bahwa dengan model PBM membuat siswa menjadi jelas dan semakin paham dengan pembelajaran yang dilakukan. Pembelajaran dengan eksplorasi lingkungan yang digunakan merupakan pengalaman keseharian siswa sehingga dapat meletakkan dasar-dasar yang nyata bagi siswa untuk berpikir. Masalah-masalah yang disajikan dalam pembelajaran adalah masalah nyata yang dialami dalam kehidupan sehari-hari karena mereka dapat belajar memecahkan masalah yang terjadi di masyarakat sehingga suatu saat ilmu yang dipelajari dapat diterapkan langsung dalam masyarakat. Pada penelitian ini, dalam proses pembelajaran berlangsung guru bertugas sebagai fasilitator dan motivator. Semua indikator pada aspek pembelajaran berpusat pada siswa semuanya yang terlihat pada setiap pembelajaran.

Selama proses pembelajaran berlangsung semua siswa terlibat dan dituntut berpartisipasi aktif. Penelitian yang dilakukan oleh Kimianti dan Prasetyo (2019) juga menyatakan model 
pembelajaran Problem-based Learning memungkinkan bagi peserta didik untuk aktif dan berani mengajukan solusi dari masalah yang sedang dihadapi. Dalam pembelajaran dengan pendekatan saintifik, inovasi aktivitas pembelajaran berbasis masalah akan diterapkan pada langkah menanya. Anjarsari (2019) menyatakan bahwa pendekatan saintifik adalah proses pembelajaran yang dirancang sedemikian rupa agar peserta didik secara aktif mengkonstruksi konsep, hukum atau prinsip melalui tahap mengamati, mengumpulkan data hingga menarik suatu kesimpulannya yang kemudian dikomunikasikan.

Hasil penelitian yang dilakukan di kelas eksperimen ditemukan beberapa hal. Kelebihan saat menerapkan aktivitas pembelajaran menanya berbasis masalah dalam pendekatan saintifk ialah siswa menjadi lebih aktif dalam bertanya dan berinteraksi dengan teman sekitarnya. Biasanya siswa yang memiliki intelektual tinggi cenderung berkumpul dalam satu kelompok sedangkan siswa yang memiliki intelektual rendah cenderung berkumpul dalam satu kelompok. Diperkuat oleh hasil penelitian Mulyani (2013) yang menemukan bahwa pembelajaran pendekatan saintifik dengan PBL membuat siswa lebih terlibat aktif dalam pembelajaran, terutama dalam kegiatan eksperimen. Siswa dapat belajar secara langsung menggunakan benda-benda konkret yang dekat dengan siswa dalam kehidupan sehari-hari.

\section{SIMPULAN}

Terdapat perbedaan yang signifikan dimensi proses kognitif antara kelompok siswa yang diberikan aktivitas pembelajaran menanya berbasis masalah dalam pendekatan saintifikdengan kelompok siswa yang diberikan aktivitas pembelajaran konvensional pada kelas IV SD di Kabupaten Buleleng Tahun Pelajaran
2016/2017. Dapat disimpulkan bahwa aktivitas pembelajaran menanya berbasis masalah dalam pendekatan saintifik dapat meningkatkan kognitif siswa IV SD.

\section{DAFTAR PUSTAKA}

Ambarsari, D. (2016). Implementasi pendekatan saintifik untuk meningkatkan keterampilan mengomunikasikan dan prestasi belajar IPA siswa kelas IV SD. Jurnal Pendidikan Guru Sekolah Dasar, 5(12), 112-121. Diunduh dari http://journal.student.uny.ac.id/ojs/ index.php/pgsd/article/view/1781.

Andriani, L. L., Suarjana, I. M., \& Lestari, L. P. S. (2017). Pengaruh model pembelajaran think pair share berbasis budaya masyarakat lokal terhadap hasil belajar Pkn siswa. Mimbar PGSD, 021(3). https://doi.org/http://dx.doi. org/10.23887/jjpgsd.v5i2.10624.

Anjarsari, E. (2019). Faktor permasalahan pendekatan saintifik $5 \mathrm{M}$ dalam pembelajaran Matematika di SMA. Jurnal Pendidikan Matematika dan Matematika, 1(1), 12-20. https://doi. org/10.30736/vj.v1i1.88.

Arianti. (2017). Urgensi lingkungan belajar yang kondusif dalam mendorong siswa belajar aktif. Didaktika Jurnal Kependidikan, 11(1), 41-62. https:// doi.org/http://dx.doi.org/10.30863/ didaktika.v11i1.161.

Astini, B. N., Nurhasanah, \& Nupus, H. (2019). Alat permainan edukatif berbasis lingkungan untuk pembelajaran saintifik tema lingkungan bagi guru paud korban gempa. Jurnal Pendidikan Anak, 8(1), 1-6.

Astraman, K. A., Dibia, I. K., \& Mahadewi, L. P. P. (2017). Pengaruh model Problem-based Learning ( $\mathrm{PbL}$ ) bermediakan gambar terhadap hasil belajar IPA siswa kelas V. Mimbar PGSD, 5(2). 
Birgili, B. (2015). Creative and critical thinking skills in problem-based learning environments. Journal of Gifted Education and Creativity, 2(2), 71-71. https://doi.org/10.18200/ jgedc.2015214253.

In'am, A., \& Hajar, S. (2017). Learning geometry through discovery learning using a scientific approach. International Journal of Instruction, 10(1), 55-70.

Jahro, S., \& Ridho, D. (2015). Penerapan model problem based learning menggunakan media exe learning untuk meningkatkan hasil belajar dan kerjasama siswa pada materi hidrokarbon. Jurnal Pendidikan Kimia, 7(3), 80-86. https://doi.org/https://doi. org/10.24114/jpkim.v7i3.4261.

Kimianti, F., \& Prasetyo, Z. K. (2019). Pengembangan e-modul IPA berbasis problem based learning untuk meningkatkan literasi sains siswa. Kwangsan, 7(2), 295728. https:// doi.org/https://doi.org/10.31800/jtp. kw.v7n2.p91--103.

Lukitasari, M., Purnamasari, I., Utami, S., \& Sukri, A. (2019). Blended-problembased learning: How its impact on students' critical thinking skills? Jurnal Pendidikan Biologi Indonesia, 5(3), 425-434. https://doi.org/https:// doi.org/10.22219/jpbi.v5i3.10048.

Mulyani, D. (2013). Hubungan kesiapan belajar siswa dengan prestasi belajar. Konselor, 2(1), 27-31. https://doi. org/10.24036/0201321729-0-00.

Nur, S., Pujiastuti, I. P., \& Rahman, S. R. (2016). Efektivitas model problem based learning $(\mathrm{PbL})$ terhadap hasil belajar mahasiswa Prodi Pendidikan Biologi Universitas Sulawesi Barat. Saintifik, 2(2), 133-141. https://doi. org/https://doi.org/10.31605/saintifik. v2i2.105.
Paut, M. S. (2016). Penerapan pendekatan saintifik pada siswa kelas IV di SD Pujokusuman 1 Yogyakarta. BASIC EDUCATION, 5(6), 511-517. Diunduh dari http://journal.student.uny.ac.id/ ojs/index.php/pgsd/article/view/1238.

Pramana, M. W. A., Jampel, I. N., \& Pudjawan, K. (2020). Meningkatkan hasil belajar biologi melalui e-modul berbasis problem based learning. Jurnal Edutech Undiksha, 8(2), 18-32. https://doi.org/http://dx.doi. org/10.23887/jeu.v8i2.28921.

Primayanti, P. E., Suarjana, I. M., \& Astawan, I. G. (2019). Pengaruh model PbL bermuatan kearifan lokal terhadap sikap sosial dan kemampuan berpikir kritis matematika siswa kelas V di Gugus V Kecamatan Sukasada. Journal of Education Technology Universitas Pendidikan Ganesha, 3(1), 28-34. https://doi.org/http://dx.doi. org/10.23887/tscj.v1i2.20417.

Putri, Swatra, \& Tegeh. (2018). Pengaruh Model Pembelajaran PBL Berbantuan Media Gambar Terhadap Hasil Belajar IPA Siswa Kelas III SD. Jurnal Mimbar Ilmu, 23(1), 53-64. https:// doi.org/http://dx.doi.org/10.23887/ mi.v23i1.16407

Rosnaeni, Muslimin, \& Saehana, S. (2018). Perbandingan keterampilan proses sains antara kelompok siswa yang diajar dengan model POE (Predict-Observe-Explain) dan model discovery pada siswa kelas X SMA Negeri 1 Sindue Tombusabora. Jurnal Pendidikan Fisika, 6(1), 43-53. https:// doi.org/http://dx.doi.org/10.24127/jpf. v6i1.1260.

Suryani, N. K., Renda, N. T., \& Wibawa, I. M. C. (2019). Pengaruh pendekatan saintifik berorientasi tri kaya parisudha terhadap penguasaan konsep IPA dan keterampilan proses sains siswa kelas V 
SD di Gugus VII Kecamatan Sukasada Kabupaten Buleleng Tahun Pelajaran 2018/2019. Journal of Education Technology, 3(1), 35-43. https://doi. org/10.23887/jet.v3i1.17962.

Sutarto, Jaedun, A., \& Raharjo, N. E. (2017). Dampak pengiring pembelajaran pendekatan saintifik untuk pengembangan sikap spiritual dan sosial siswa. Cakrawala Pendidikan, 36(1), 44-56. Diunduh dari https://journal.uny.ac.id/ index.php/cp/article/view/12792/pdf.

Widnyani, I. I. D.A. R., Dantes, N., \& Tegeh, I. M. (2015). Pengaruh pendekatan saintifik terhadap sikap spiritual siswa dengan kovariabel intensitas hubungan dalam pola asuh keluarga. MIMBAR
PGSD, 3(1). Diunduh dari https:// ejournal.undiksha.ac.id/index.php/ JJPGSD/article/viewFile/5635/4105.

Widodo, W. (2016). Wujud kenyamanan belajar siswa, pembelajaran menyenangkan, dan pembelajaran bermakna di sekolah dasar. Ar-Risalah, 18(2), 22-37. Diunduh dari http:// ejournal.iaiibrahimy.ac.id/index.php/ arrisalah/article/view/123/137.

Wulandari, I. G. A. A. M., Sudatha, I. G. W., \& Simamora, A. H. (2020). Pengembangan pembelajaran blended pada Mata Kuliah Ahara Yoga Semester II di IHDN Denpasar. Jurnal Edutech Undiksha, 8(1), 1-15. 